\section{SELF-REGULATED \\ LEARNING BY THAI UNIVERSITY STUDENTS IN AN EFL EXTENSIVE READING PROGRAM}

\author{
Chitchon Pratontep ${ }^{1}$ \\ Apasara Chinwonno ${ }^{2}$
}

\begin{abstract}
This study aims to investigate students' self-regulated learning strategies and English reading comprehension in an ER program. There were 38 students participating in the study. The students were divided into upper and lower level groups according to their English reading comprehension pre-test mean scores. After 10 weeks of ER, findings show that there were significant differences between the students' English reading comprehension pre- and post-test mean scores, especially for the lower level group. Findings from the self-regulated learning interview schedule indicate that students reported frequently using metacognitive and performance regulation strategies. In addition, from the students' verbal protocols of reading, they reported using self-regulated learning strategies in the performance or volitional control phase more often than in the forethought or selfreflection phases. Pedagogical implications are presented and discussed.
\end{abstract}

${ }^{1}$ Graduate student, Moderate/Severe

Disabilities Educational Specialist Program,

California State University Los Angeles, USA

${ }^{2}$ Associate Professor, Department of

Curriculum Instruction and Educational

Technology, Faculty of Education,

Chulalongkorn University, Bangkok, Thailand

\section{Introduction}

The average EFL proficiency of Thai students is often found to be low. Educational Testing Service (2007) reports that the 2005-2006 computer-based TOEFL mean score of Thai students was only 200. This indicates that Thai students' English proficiency was below the effective operational proficiency level according to the Common European Framework Reference (Educational Testing Service 2004). The study by Prapphal and Opanon-amata (2002) also found that Thai students scored below 500 on the Chulalongkorn University Test of English Proficiency (CU-TEP) as equated to the paper-based TOEFL score. According to Bernhardt (2005), L2 proficiency such as that gauged by TOEFL and CU-TEP may account for 30 percent of the variables which contribute to second language reading abilities. In other words, L2 proficiency may have an impact on the ability to read in a second language. Therefore, it is possible that Thai students with low English proficiency may experience frustration reading English.

In Thailand, EFL reading instruction primarily focuses on a detailed study of vocabulary and comprehension, but many reading researchers argue that this intensive reading instruction may not be sufficient for EFL students (Day and Bamford 1998, Grabe 2002, Coady 1997, Nuttall 1996). Eskey 1987 recommends that people learn to read by reading. Krashen (2004) further explains that EFL students need to gain exposure to a large amount of comprehensible input to improve their reading comprehension. Although Krashen's hypothesis of comprehensible input may be controversial, it is undeniable that exposure to L2 can contribute to reading comprehension abilities. Therefore, 
an approach to reading instruction that may address the low reading abilities of Thai students may be Extensive Reading.

\section{Extensive reading (ER)}

ER is an approach to teaching reading in which students are exposed to a large amount of reading materials. The purpose is to gain comprehension and pleasure in reading. The ultimate goal of ER is to give students an opportunity to read in a second language and become avid readers (Day and Bamford 1998). ER helps make reading more meaningful and engaging (Nassaji 2003, Day and Bamford 1998). It may lead to gains in vocabulary knowledge (Coady 1997, Cho and Krashen 1994, Nation 1997, Nation and Ming-tzu 1999), and reading speed and ability (Mason and Krashen 1997). In addition, a positive attitude towards reading may develop (Mason and Krashen 1997, Day and Bamford 1998, Takase 2001). Several researchers agree that although this may not necessarily generate the highest level of competence, it is an indispensable component of reading instruction, which will pave the way for higher levels of language proficiency (Nuttall 1996, Coady 1997).

In ER, as Krashen (2003) proposes, people acquire language only when they understand what they read. Consequently, EFL students in ER need to read a considerable number of books at the level equivalent to their reading abilities in order to improve comprehension. Anderson (1996) states that the number of books students read significantly correlates with their improvement in reading comprehension. Moreover, students must be able to choose reading material with respect to their interests and reading abilities since the purpose of reading in ER is for pleasure
(Day and Bamford 1998). Nevertheless, Grabe and Stoller (1997) advise that students do not become proficient readers by reading extensively in only one genre; they need exposure to other genres to improve their reading comprehension abilities.

Students may be reluctant to read as they may be at beginning or low intermediate reading comprehension levels (Hudson 2007). To encourage students to read, a teacher needs to be a model reader (Day and Bamford 1998). In addition, the goal for students should be the number of words, pages, or books read. Post-reading activities should be of low accountability. Grades or rewards should not be offered for students' reading since they have proven to be ineffective in promoting reading achievement or positive motivation to read. Students may be asked to keep a record of time and the amount of reading done, or to write a short summary of a book or a part of it that they have read (Susser and Robb 1990, Mason and Krashen 1997, Day and Bamford 1998, Sheu 2003).

Nevertheless, Day and Bamford (2000) caution that introducing ER in a nonreading culture or in one that does not attach importance to reading for pleasure makes the task of EFL reading teachers more complex. The National Statistical Office survey (2005) reveals that 30.9 percent of Thais or approximately 18 million people do not read because they dislike reading or they prefer to watch television. This reflects that a number of Thais are not likely to find reading pleasurable in their own language. Similarly, they are not likely to find reading in English pleasurable (Morrow and Gambrell 2000). Furthermore, as ER occurs most of the time outside of the 
classroom, EFL students may not have the discipline to maintain the regular habit of reading. Robb (2002) found that Japanese students may read just to fulfill the requirements of the course.

To implement ER in Thailand, ways to promote regular reading must be understood. However, studies of ER have primarily focused on the effects of ER on reading comprehension and attitudes towards reading (Susser and Robb 1990, Day and Bamford 1998, Krashen 2004). There is very little evidence of what students in ER do outside of the classroom to make reading a regular habit. Without knowledge of how students regulate their reading outside of the classroom, the prospects for successful ER implementation may be obscure.

\section{Self-regulated learning}

Baker (2002) advises that independent reading is not sufficient. She asserts that students need metacognitive strategies, specifically in knowing how to regulate their cognition. In a similar view, Brown (2002) supports the teaching of selfregulation to improve reading comprehension since poor readers cannot make use of different strategies and they need to be taught how to use these strategies effectively.

Self-regulated learning is viewed by social cognitive theorists as a process in which individuals are metacognitively, motivationally, and behaviorally active participants in their learning process (Bandura 1986). This involves an interdependent interaction among person, environment, and behavior. Each component interacts with the other to modify or change behaviors so that a learning goal can be reached (Bandura 1986). The self-regulated learning process involves three major phases: forethought in which students prepare themselves for learning by planning or setting a goal, "performance" or "volitional control" in which students focus and monitor their learning methods or strategies, and "selfreflection" in which students evaluate their performance and react accordingly (Zimmerman 2000). Research has shown that self-regulated learning plays an important role in the academic accomplishments of successful students (Pintrich and De Groot 1990, Schunk and Zimmerman 1994). These students proactively set specific learning goals, employ strategies, constantly monitor, and reflect on progress (Zimmerman, Bonner and Kovach 2003).

The measurement of self-regulated learning strategies involves two properties"aptitude" and "event" (Winne and Stockley 1998). An aptitude describes the cognition or motivation that is involved when students participate in future learning activities, or what students predict they will do in learning activities (Winne and Stockley 1998). For example, if students report reading a title and book cover, this may indicate students' goalsetting and planning. An event describes the operations of cognition in learning activities, or what students actually do when they learn (Winne and Perry 2000). For example, students may be asked to think aloud and report what they do before reading a book to demonstrate the strategies in the planning phase. The measurement of these two properties of self-regulated learning strategies will provide a framework for the investigation of students' self-regulation in this study.

\section{Purposes}

A study of students' self-regulated learning 
strategies in ER can provide insights into how Thai students regulate themselves while reading outside the classroom. It was guided by the following research questions:

1. To what extent does ER improve a student's EFL reading comprehension?

2. What are self-regulated learning strategies employed by upper and lower level groups after participating in ER?

\section{Method}

\section{Participants}

The participants were 38 undergraduate students from the Faculty of Commerce and Accountancy in a Thai public university. Based on their English reading comprehension pre-test scores, students were classified into upper and lower level groups. The upper level group included students at $+0.3 S D$ above the mean score, while the lower level group included students at $-0.3 S D$ below the mean score. Students in the middle level group continued to participate in ER but were excluded from the self-regulated learning interview schedule and verbal protocols of reading. There were fourteen upper level students (Mean=33.21, $\mathrm{SD}=4.61)$ and fifteen lower level students (Mean=19.67, $\mathrm{SD}=2.092$ ).

\section{Setting}

An ER program for this study was supplementary to the foundation level English course for first-year university students. The design of the ER program was based on the following four components.
"Reading materials". The ER classroom library consisted of graded readers and authentic books from a variety of genres such as romance, drama, detective, thriller, horror, biography, business, and science fiction. In the beginning, students started reading a book of their interest. As the semester progressed, they were encouraged to read books in other genres to increase their exposure to vocabulary and different types of books.

The classroom library contained graded readers from the starter level to level 6 . The readability of each authentic book was determined through the Flesch-Kincaid Index which calculates from the number of syllables, words, and sentences in a text. The readability levels ranged from 4.5 to 10. The level was printed on a sticker and put on the spine of each book. With respect to resource management, the books were arranged on the shelf according to level. Each shelf was dedicated to only one level, and it contained both graded readers and authentic books. Library borrow-return cards were affixed to the inside of the back covers. Students were allowed to check out a book for a period of one week with unlimited renewals.

Comprehensible input. Students extensively read graded readers or authentic books at their own reading levels to increase their exposure to English reading texts. The students were asked to read at least 1,000 pages over 10 weeks.

Feedback. The teacher's role was to provide frequent feedback through a weekly reading portfolio to ensure that students maintained the habit of reading regularly. During each week, students kept a record of the number of pages they read, the time they spent reading, the level of the book they were reading, a 50-word 
summary of what they read, and a reflection on what they had read. The purpose was to monitor students' reading, so students would be able to complete the reading portfolio quickly. The teacher gave feedback on the reading portfolio, encouraging or recommending ways for better success with reading comprehension. An individual consultation was also arranged for students who needed assistance in understanding the story or adjusting reading level. Peer feedback was also implemented in this study. During resource management activities which occurred in the last 15 minutes of class, students shared information and recommended books that they had read to friends. Peer feedback also helped students learn how to employ comprehension strategies. Peers shared successful and unsuccessful strategies they had experimented with during the week.

Encouragement. At the beginning of each class, the teacher introduced a new book and discussed with students the book that they were reading during that week and discussed elements such as characters, plot, or cultural background. While students silently read their books, teachers also read to create a positive reading environment and to inform students that ER was important for everyone. The last 15 minutes of every class involved resource management activities such as returning and borrowing books. During this time, the teacher and students shared information about interesting books, a book-sharing activity that would assist students in selecting new books.

ER lessons also include reading tasks which focus on selecting appropriate books and improving reading comprehension. However, Thai students are often reluctant to take the initiative in selecting a text because in their experience, reading is likely to have always been teacherdirected. Therefore, they may have difficulty determining their reading level and, consequently, finding appropriate and enjoyable books. The first ER task was to raise students' reading awareness of their interests using a reading survey in both Thai and EFL. Then, students selfassessed their reading level by reading all excerpts from the graded readers from the starter level to reading levels 6 . They also observed the amount of unfamiliar vocabulary and their general understanding of the story. This process of selfassessment helped students determine their appropriate reading level. To raise students' awareness of books, ER lessons included encouraging reading tasks such as analyzing the front and back of book covers and making predictions based on the story title.

Among other goals, ER activities in this study were designed to promote reading comprehension. Reading strategies such as summarizing, determining the meaning of unfamiliar vocabulary, and noticing and solving reading problems were taught to students. Students were encouraged to use these strategies throughout the week. Then, they learned how to effectively employ the strategies by discussing their experiences with successful and unsuccessful strategies with their peers.

\section{Data collection and analysis}

Data collection consisted of two parts: English reading comprehension and selfregulated learning strategies.

\section{English reading comprehension}

For English reading comprehension, "an 
English reading comprehension test" was adapted from the reading section of Chulalongkorn University Test of English Proficiency (CU-TEP), an institutional standardized English proficiency test. It contains 60 multiple-choice questions which target different aspects of reading comprehension: word recognition, and literal, interpretive and critical comprehension. Parallel forms were administered in pre- and post-tests. The reliability coefficient of the English reading comprehension pre-test was .83 , and .87 for the English reading comprehension post-test, which means that both tests were reliable. A dependent samples t-test was used to study the improvement in reading comprehension.

\section{Self-regulated learning strategies}

"A Self-Regulated Learning Interview Schedule-SRLIS" (Zimmerman and Martinez-Pons 1986) measures the aptitude property of self-regulated learning. The SRLIS was translated into Thai and adjusted to six learning contexts relating to ER: 1) Reading in class, 2) Completing a reading portfolio, 3) Finishing a book, 4) Preparing for exams, 5) Lacking motivation to read, and 6) Reading outside of the classroom.

Since data from an SRLIS could be overwhelming, representatives from each group were selected. Students' English reading comprehension pre-test scores were arranged from the highest to the lowest. Then, every other student was selected to represent their groups. Fourteen students from the upper level group $(n=7)$ and the lower level group $(n=7)$ were asked to report what they would usually do in the six situations. Fourteen self-regulated learning strategies proposed by Zimmerman and Martinez-
Pons (1986) guided the coding. Once a strategy was mentioned, students had to estimate the frequency of the strategy from seldom $=1$ to most of the time $=4$.

Thereafter, to examine the three components of self-regulation-person, behavior, and environment, the 14 strategies were classified into a) metacognitive regulation - organizing and transforming, rehearsing and memorizing, goal-setting and planning, and keeping records and monitoring; b) performance regulation-self-evaluation and self-consequences; and c) learning environment regulation-environmental structuring, seeking information, reviewing, and seeking assistance (Zimmerman 1989). Four coded interview transcriptions were randomly selected and sent to two independent raters to assess the reliability of the coding. The reliability coefficient was .83 indicating that the coding categories were highly consistent. Data from the SRLIS were analyzed using descriptive statistics.

"Verbal Protocols of Reading" measured the event property of self-regulated learning of the upper and lower level groups. The students read an excerpt of a level-six graded reader titled The Runaway Jury by John Grisham; as they read, they were asked to frequently pause and report their thoughts. Data from the protocols was transcribed and coded according to the constructively responsive reading strategies (Pressley and Afflerbach 1995), portraying what an ideal skilled reader would do. From the first coding of the verbal protocols, it was found that recall strategies were widely used by students; therefore, the coding of this strategy was revised and six sub-strategies were assigned and listed as shown in Table 3. Four coded verbal protocols were randomly selected and sent to two 
independent raters to assess the reliability of the coding categories. The reliability coefficient of the verbal protocols coding was .87 , which means that the coding categories were highly consistent. Once the verbal protocols were coded, data was calculated in frequency. To examine the even property of self-regulated learning, these reading strategies were categorized into three phases: forethought, performance or volitional control, and self-reflection.
Cohen's $d$ suggests that the improvement was small $(d=.21)$.

The improvement of the upper level group on the English reading comprehension post-test was not significantly different $t(13)=.968, \mathrm{p}>0.05$. The effect size also indicates that the difference between the English reading comprehension pre- and post-test mean scores was minimal $(d=.21)$.

Table 1: Findings of English Reading Comprehension Pre- and Post-tests.

\begin{tabular}{llllllllll}
\hline & & $n$ & Mean & SD & $T$ & $d f$ & Sig. & $\begin{array}{c}\text { Mean } \\
\text { difference }\end{array}$ & $d$ \\
& & & & & & & & & \\
\hline ER & Pre-test & 38 & 26.61 & 7.19 & 2.923 & 37 & .006 & 1.97 & .21 \\
& Post-test & 38 & 28.08 & 6.78 & & & & & \\
\hline Upper & Pre-test & 14 & 33.21 & 4.61 & .968 & 13 & .351 & 1.15 & .21 \\
& Post-test & 14 & 34.36 & 6.08 & & & & & \\
\hline Lower & Pre-test & 15 & 19.67 & 2.92 & 3.377 & 14 & .005 & 3.93 & 1.0 \\
& Post-test & 15 & 23.60 & 4.69 & & & & & \\
\hline
\end{tabular}

$p<0.05$

\section{Findings}

\section{English Reading Comprehension}

Table 1 reveals that students' English reading comprehension post-test mean score was significantly higher than the pre-test mean score $t(37)=2.923, \mathrm{p}<0.05$. However, the effect size calculated by
The lower level group, on the other hand, made a significant improvement in its English reading comprehension post-test $t(14)=3.377, \mathrm{p}<0.05$. The effect size was large $(d=1.0)$. Nevertheless, since this study was of a one-group pre- and posttest design, generalization of the results is limited and should be interpreted with cautions. 


\section{Self-regulated learning}

The findings of self-regulated learning strategies consist of two parts: aptitude and event.

\section{Aptitude}

For an aptitude measurement, Table 2 shows the reported use of self-regulated learning strategies by the upper and lower level groups. The upper level group reported using self-evaluation, goal-setting and planning, and environment structuring strategies the most often; the lower level group reported using organizing and transforming, goal-setting and planning, self-evaluation, and environment structuring strategies the most often. Neither groups reported using reviewing tests or textbooks.

\section{Metacognitive regulation}

The upper level group reported using strategies to regulate metacognition more frequently than the lower level group (see Table 2). The upper level group employed goal-setting and planning strategies the most often. Goal-setting included establishing a number of pages, or deciding how much time to read each day. In the following excerpt, an upper level student reported setting a specific goal by trying to read two chapters per day to help her finish reading a book each week; the lower level student's goal, on the other hand, was not clearly specified.

\section{Goal-setting strategy}

Upper level student \#3: "When I check out a new book, I find out how many chapters there are. Then I will figure how many chapters I should be able to cover in one week. On average, I read two chapters everyday."

Lower level student \#6: "I just tried to read as much as I could during the week, especially on the day before class, I would try to finish a book, so I could write a summary and turn in a reading portfolio."

\section{Performance regulation}

The upper level group also used strategies to regulate performance more frequently than the lower level group. The upper level group tended to use self-evaluation strategies to control performance; the lower level group reported seldom using strategies in this category. In the sample response of an upper level student, the student described how he evaluated his understanding of the story by constructing a brief summary of each section he had read. A lower level student reported using a similar strategy, but she did not seem to have any strategic method to deal with the problem.

\section{Self-evaluation strategy}

Upper level student \#6: "While I was reading, I usually paused at a quarter or half of a page to tell myself if I understood the story. It's like a very short summary, so that I wouldn't get confused. If there were some problems, I would reread that part."

Lower level student \#3: "If I read and could not understand some parts of a book, I would reread that part again. I don't know how to explain. I just read it again and sometimes I could understand the story." 
Table 2: Self-regulated Learning Interview Schedule Results

\begin{tabular}{l}
\hline An Aptitude: Self-regulated Learning Interview Schedule \\
\hline Items \\
\begin{tabular}{lllll}
\multicolumn{4}{l}{ Upper $(\mathrm{n}=7)$} & Lower $(\mathrm{n}=7)$ \\
\cline { 2 - 5 } & Mean & SD & Mean & SD \\
\hline
\end{tabular}
\end{tabular}

\section{Metacognitive regulation}

1.1. Goal-setting and planning

$\begin{array}{llll}2.71 & 0.76 & 2.00 & 1.41\end{array}$

1.2. Organizing and transforming

$\begin{array}{llll}2.57 & 1.40 & 2.29 & 1.11\end{array}$

1.3. Keeping records and monitoring

2.57

1.27

0.86

1.46

1.4. Rehearsing and memorizing

0.57

1.51

0.00

0.00

\section{Performnce regulation}

2.1. Self-evaluation

2.2. Self-consequences

\section{Learning environment regulation}

3.1. Environment structuring

3.2. Seeking peer assistance

3.3. Seeking teacher assistance

3.4. Seeking adult assistance

3.5. Reviewing tests

3.6. Reviewing notes

3.7. Reviewing textbooks

3.8. Other persons' initiations

\section{Learning environment regulation}

The upper level group reported frequently using environment structuring strategies to regulate the learning environment; the lower level group seldom used strategies in this category. Both groups scarcely used social environment strategies such as seeking peer or adult assistance and reviewing strategies to facilitate their learning. In the following response, an

$\begin{array}{llll}3.14 & 1.46 & 1.71 & 1.70 \\ 2.29 & 1.60 & 1.14 & 1.46\end{array}$

$\begin{array}{llll}2.71 & 0.76 & 1.71 & 1.25\end{array}$

$\begin{array}{llll}1.29 & 1.60 & 0.00 & 0.00\end{array}$

$\begin{array}{llll}0.00 & 0.00 & 0.43 & 1.13\end{array}$

$\begin{array}{llll}1.00 & 1.73 & 0.00 & 0.00\end{array}$

$\begin{array}{llll}0.00 & 0.00 & 0.00 & 0.00\end{array}$

$\begin{array}{llll}0.43 & 1.13 & 0.43 & 1.13\end{array}$

$\begin{array}{llll}0.00 & 0.00 & 0.00 & 0.00\end{array}$

$\begin{array}{llll}0.00 & 0.00 & 0.43 & 1.13\end{array}$

upper level student demonstrated how she regulated her reading time to maintain a regular reading habit.

Environment structuring strategy

Upper level student \#8: "I read after 9 p.m. Usually I get home around 6 p.m. and I give myself a three-hour break to relax, have dinner, and chat with friends. Then I start reading until I finish 
what I plan to. This way I don't leave things to the last minute."

Lower level student \#3: "I don't have a regular reading place, but I often read before I go to bed. I just read whenever I can."

In sum, from the measurement of an aptitude property of self-regulated learning, the results show a noticeable pattern in the upper and lower level groups' use of selfregulated learning strategies. The upper level group frequently used strategies to regulate every category of self-regulated learning to enhance learning while the lower level group infrequently used strategies to control its learning. In metacognitive regulation, the upper level group used goal-setting and planning strategies; in performance regulation, the group used self-evaluation strategies; and in learning environment regulation, the group used environment structuring strategies.

\section{Event}

For an event measurement of self-regulated learning, not all of the 15 strategies were evident from the verbal protocols. From Table 3, eight strategies were utilized by the students in both upper and lower level groups to varying degrees. Activating prior knowledge was used once by the upper level group, while looking for important information was used once by the lower level group. Five were not found in the data-overviewing text, revising prior knowledge, evaluating text, conversing with author, and anticipating use of knowledge. The most frequently used strategies were using recall strategies and determining word meaning while the least frequently used strategies were relating text to prior knowledge, relating text to text, and inferring.

\section{Forethought}

Neither the upper nor lower level groups made frequent use of strategies at this phase to control their learning. Only the upper level group reported using "the activating prior knowledge strategy" once. In the following response to the text, an upper level student showed that the content in this part of the text prompted her to think about U.S. legal matters.

\section{Activating prior knowledge strategy}

Text: And now, the lawyers were pursuing them. The survivors of dead smokers were suing them

Upper level student \#8: “Oh so this is going to be about lawyers suing these tobacco companies. I have read that in the U.S., people sue one another a lot, and these people in the story are probably doing the same thing, suing the companies that smoking causes diseases."

\section{Performance or volitional control}

Two strategies-interpretive conclusion and determining word meaning-were prominently used by students in both groups. Both the upper and lower level groups relied on the "interpretive conclusion strategy" the most often. Interestingly, the lower level group used this strategy slightly more frequently than the upper level group. In the following response, the upper and lower level students show how they constructed a brief conclusion while they read. 
Interpretive conclusion strategy

Text: To help fight these court cases, the Big Four had put together a sum of money called The Fund.
Upper level student \#6: "So they need to gather a lot of money to pay for all of the legal fees and expenses.

Lower level student \#3: "So these four cigarette companies had to help one another. They chip in money to handle these lawsuits.

Table 3: Verbal Protocols of Reading Results

\begin{tabular}{lll}
\hline An Event: Verbal Protocols of Reading & \\
\hline Items & Upper $(n=7) \quad$ Lower $(\mathbf{n}=7)$ \\
\cline { 2 - 3 } & Frequency & \\
\hline
\end{tabular}

\section{Forethought}

1.1. Overviewing text 00

1.2. Activating prior knowledge $\quad 1 \quad 0$

2. Performance or Volitional Control

2.1. Looking for important info $\quad 0 \quad 1$

2.2. Relating text to text 4

2.3. Relating text to prior knowledge $2 \quad 1$

2.4. Revising meaning $\quad 8 \quad 4$

2.5. Revising prior knowledge $\quad 0 \quad 0$

2.6. Inferring 3

2.7. Determining word meaning $\quad 17 \quad 52$

2.8. Using recall strategies $268 \quad 274$

2.8.1 Interpretive conclusion $\quad 238 \quad 241$

2.8.2 Rereading 005

2.8.3 Paraphrasing $\quad 3 \quad 4$

2.8.4 Self-questioning $\quad 10 \quad 7$

2.8.5 Deliberating $\quad 7 \quad 7$

2.8.6 Making notes $10 \quad 10$

2.9. Changing strategies $11 \quad 8$

\section{Self-Reflection}

3.1. Evaluating text 00

3.2. Reflecting $11 \quad 6$

3.3. Anticipating use of knowledge 00

3.4. Conversing with author $\quad 0 \quad 0$ 
Both the upper and lower level groups also frequently employed "the determining word meaning strategy". Again, the lower level group tended to use this strategy more frequently than the upper level group. In the following excerpts, upper and lower level students encountered an unfamiliar word and used their vocabulary knowledge to guess the meaning of the word.

\section{Determining word meaning strategy} jurors?

Text: What about the

Upper level student \#8: "Juror. This word is very familiar. I think it's like jury or those people who judge if a person is guilty or not."

Lower level student \#8: "This is probably one of the persons in the legal process."

\section{Self-reflection}

Both the upper and lower level groups relied mainly on "the reflecting strategy". The upper level group used this strategy just slightly more often than the lower level group. Other strategies were not evident in the verbal protocols. In the following response, upper and lower level students present how they paused to reflect on their understanding of the story.

\section{Reflecting strategy}

Text: "A brief summary, gentlemen. At the moment, the entire defense team is working non-stop, and this will continue through the weekend.
Investigations into possible jurors are on schedule. Trial lawyers are ready, witnesses are prepared, all our experts are already in town."

Upper level student \#6: "So these four guys have been waiting for Fitch to tell them this news. He is the one who manages these lawsuits and tries to get everything ready for the trial. He has everything prepared, lawyers, witnesses, and experts."

Lower level student \#3: " $A$ short summary. So the team is working all the time even on the weekend. Work is on schedule and things are ready for the trial."

To conclude, the upper and lower level groups reported using similar self-regulated learning strategies to regulate their learning. However, the upper level group used self-regulated learning strategies more frequently to regulate its learning in two categories - metacognitive and performance regulation. Nevertheless, the verbal protocols show inconsistent findings; the students did not actually use the strategies they reported in the SRLIS. In contrast to the frequent use of goal-setting and planning strategies in the SRLIS, the strategies in the forethought phase were hardly used by the upper level group. Similarly, strategies in the self-reflection phase were underused. The students reported using strategies which clustered in the performance or volitional control phase.

\section{Discussion}

The discussion of findings will be presented according to the two components-English reading comprehension and self-regulated learning strategies. The comparison of 
English reading comprehension pre- and post-tests mean scores shows significant differences especially for the lower level group. However, the major findings of this study emerge from the self-regulated learning results. For an aptitude property, the upper level students reported actively using self-regulated learning strategies to regulate their metacognition and performance more often than the lower level did. For an event property, both groups employed strategies mostly in the performance or volitional control phase.

\section{English reading comprehension}

The findings show that the English reading comprehension pre- and post-test mean scores differed significantly. This is consistent with other studies in which ER enhanced reading comprehension (Tanaka and Stapleton 2007, Sheu 2003, Bell 2001, Hayashi 1999, Lituanas, Jacobs and Renandya 1999, Walker 1997, Sims 1996, Schackne 1994). Since students have extensive access to comprehensible input from reading graded readers and books, their reading comprehension was improved. Anderson (1996) explains that the amount of book reading is substantially correlated with improvement in reading comprehension. Students in an EFL setting can especially benefit from this constant exposure to reading books in ER (Anderson 1996). In Thailand, the only exposure to English texts that students have may be from reading English texts in class. This may not be sufficient to help students improve their reading comprehension because they will have fewer opportunities to practice their reading skills and strategies. Therefore, the findings emphasize an important role for ER in EFL classrooms to help improve students' English reading comprehension.

Moreover, the findings argue for the notion that one book doesn't fit all. Students differ greatly in academic background, from those who struggle to read to those who excel in all aspects of their reading. In traditional EFL reading instruction, this variable is hardly recognized, and students have to read the same text regardless of their interest and reading abilities. By allowing students to choose their own book, ER creates a positive reading environment by addressing students' different interests, strengths, and weaknesses. To exemplify, by providing access to texts of various reading levels and genres, students of high reading ability can obtain the benefits of reading interesting and challenging texts while students of low reading ability do not feel discouraged by struggling with books above their reading levels or that do not interest them. Consequently, students may be more motivated to read while regularly practicing their reading skills and strategies.

Bernhardt (2005) also stresses the role of other variables besides language proficiency in second language reading. She explains that L1 language proficiency and L2 language proficiency may account for $20 \%$ and $30 \%$ of second-language reading proficiency, respectively. The rest may come from other external variables such as students' comprehension strategies, interest, and motivation. Such external variables as the reading environment may also contribute. In their study, Tella and Akande (2007) found that students may not read because they do not have access to interesting material in their reading environment. Mulholland (2006) also agrees and points out the importance of structuring a positive reading environment. She suggests that only the choice of books may be insufficient to promote reading comprehension. The key variable may be 
the influence of a positive reading environment which helps students regulate their reading, and enhance reading comprehension; eventually it may help transform students into avid readers.

Thus, to implement ER in Thailand, students must have abundant opportunities to access English texts to improve English reading comprehension abilities. However, teachers also need to consider students' differences and allow them to select books of their interest and level of reading comprehension ability. More importantly, the setting of ER needs to provide positive a reading environment to encourage students to read.

\section{Reading abilities and test scores}

From the English reading comprehension pre- and post-tests, the upper level group's English reading comprehension increased only minimally. This may be due to the short duration of ER in this study. Krashen (2007) and Smith (2006) report that ER studies which were shorter than 7 months did not find any significant improvement in reading comprehension. Students, especially in EFL countries, may need more time to gain exposure to reading texts before a significant improvement in reading comprehension takes place. This small increase may also signify that the students began to progress; if they continue in $E R$, their reading comprehension improvement could be more conspicuous. In contrast, the increase between the lower level group's English reading comprehension pre- and post-test mean scores was large, which is similar to the results of other studies in ER (Sheu 2004, Takase 2003, Maxim 1999, Kern 1989). In other words, students at a low reading comprehension level should be encouraged to participate in ER to obtain the potential benefits of reading comprehension improvement.

Nonetheless, there is also a statistical explanation regarding this phenomenon. Since students in this study were from the upper and lower level groups, it is possible that regression towards the mean may occur. Fraenkel and Wallen (2000) explain that the post-test scores of the extremely high or low ability groups will regress closer to the mean. In this study, the students' performance on English reading comprehension may have been slightly affected by this statistical phenomenon. The increase in the English reading comprehension pre- and post-tests scores of the lower level group was large; on the other hand, the increase in the English reading comprehension pre- and post-tests scores was minimal for the upper level group.

\section{Self-regulated learning}

Students' self-regulated learning strategies will be discussed in the context of the two properties of self-regulated learning strategies: aptitude and event.

\section{Aptitude}

The findings from an aptitude measurement of self-regulated learning strategies show that the upper and lower levels group actively used strategies in two self-regulated learning categoriesmetacognitive and performance regulation. The upper level group frequently used goal-setting and planning, self-evaluation, and environment structuring strategies. On the other hand, the lower level group frequently used goal-setting and planning, organizing and transforming, and environment structuring.

The less frequent use of strategies in metacognitive and performance regulation 
by the lower level students reflects that their approach to reading may be unpolished. Although they reported somewhat frequent use of strategies in the metacognitive regulation category, they did not frequently employ strategies in the performance regulation category. That is, these students may have a goal for their reading, but they may not have any specific strategies to monitor and control their performance to achieve their goals. According to Zimmerman (1989), the regulation of metacognitive and performance is critical and influential to other categories and may be an indication of high achieving students. Therefore, it is important that students, especially those with low English reading abilities be taught how to set goals and monitor their performance to attain the desired learning outcomes.

In addition, students in both groups seem to recognize only the regulation of their physical environment. There was inconsistency in the low or non-existing report of social environment regulation as indicated by the infrequent use of seeking assistance strategies. Zimmerman and Martinez-Pons (1988) claim that selfregulated learners should actively seek out information and assistance when needed. However, this rare use of social strategies may be due to the nature of ER in which reading is independent, private, and pleasurable. Students read at or slightly below their level with little or no difficulty in interpreting texts (Day and Bamford 1998). Therefore, students may not often seek assistance from other people while reading in ER.

\section{Event}

The findings from an event measurement of self-regulated learning strategies show that students did not make consistent use of all strategies in the three self-regulated learning phases - forethought, performance or volitional control, and self-reflection. The strategies were hardly used in the forethought and self-reflection phases although this was apparent in the SRLIS. This may suggest that Thai students tend not to set goals or reflect on their learning. These strategies may need to be explicitly taught to students. Bandura (1991) illustrates that students of a high reading comprehension level may form learning goals which are specific and proximal to progress towards the distant goals. These students also report having a mastery goal orientation or trying to understand the subject rather than just trying to achieve high grades (Pintrich and De Groot 1990).

In the performance or volitional control phase, the lower level group reported using strategies more frequently than the upper level group. This may be explained by Stanovich's (2000) compensatory processing. The lower level group may have used more self-regulated learning strategies to compensate for its limited language proficiency. The model proposed that the lower level group's limited knowledge source in one area would be automatically assisted by other knowledge sources. From the verbal protocols, the lower level group may rely on other strategies to assist its comprehension, thus, resulting in frequent use of self-monitoring strategies such as using recall.

Furthermore, the use of strategies in the performance or volitional control phase suggests that Thai students may read mainly for literal comprehension. Students may be occupied with determining word meaning and trying to understand the story. There was rare use of strategies for critical comprehension such as relating 
text to prior knowledge or inferring. That is, Thai students general read English texts without interacting with the texts to fully grasp in-depth understanding.

In the self-reflection phase, both upper and lower level groups only used the reflecting strategy in the verbal protocols. Paris, Wasik and Turner (1996) explain that in pleasure reading, the post-reading strategies may only be an appreciation of the text. Nonetheless, reflecting on text understanding can help students determine whether they adequately understand the text, or whether they need to reread some parts of the text. Again, this evidence from the self-reflection phase reiterates that Thai students appeared to focus only on trying to construct literal understanding of the text.

In conclusion, the findings show a significant gain in English reading comprehension. If students are provided with a positive reading environment through access to interesting reading materials, they may gain the benefits from exposure to English texts. The findings of the upper and lower level groups also reveal that the lower level group may benefit to a greater extent from reading English texts than the upper level group. Moreover, the findings of self-regulated learning strategies highlight the need to teach Thai students to regulate their learning environment and to develop critical reading comprehension.

\section{Pedagogical implications}

Three pedagogical implications can be made from this study. First, a positive reading environment plays a significant role in promoting students' reading comprehension. Greaney (1996) underlines the impact of an adverse reading environment. The lack of appropriate reading material or space may cause poor reading comprehension. For instance, students may not be motivated to read if a reading class does not provide an opportunity to select interesting material to read for pleasure. Consequently, everyone in the learning community should help create a positive EFL reading environment. For a positive physical reading environment, a variety of interesting reading material and suitable space for reading should be made available. A school library needs to include material that can cater to students' different interests and reading levels. For a positive social reading environment, teachers and family need to be model readers and to offer assistance when needed.

Furthermore, students must read a large number of books to improve their reading comprehension since people learn to read by reading (Eskey 1987). Students' development of reading comprehension essentially depends upon their exposure to reading material (Cunningham and Stanovich 1991). Therefore, it is important that students maintain the habit of reading regularly. At the same time, students need to regulate themselves while reading since ER is primarily a private and individual activity (Day and Bamford 1998). Before reading, students should set a goal and generate a plan to reach that goal. While reading, they should learn to monitor their comprehension and use a variety of strategies to aid their comprehension. After reading, they need to reflect on their learning and try to identify strategies that have contributed to the success or failure of their reading.

Finally, EFL reading educators should support ER. Since EFL students have limited exposure to reading materials 
outside of class, ER should be integrated into every EFL class. The findings also suggest that ER needs to last for at least one year to see noticeable improvement in reading comprehension (Krashen 2004). Reading material needs to cover a range of genres and vary in readability levels to provide an opportunity for students to progress at their own pace. Explicit strategy instruction should also be implemented as EFL students need more time and practice to learn strategies. For example, through thinking aloud, students can observe how and when a strategy should be employed. Thus, students can learn to recognize and choose appropriate self-regulated learning strategies.

\section{Conclusion}

This study explored students' selfregulated learning strategies and English reading comprehension in ER. It concluded that there is evidence to support the benefits of ER. ER may provide a positive reading environment for students with different reading abilities and interests. ER can be particularly beneficial to a lower level group as shown by the large increase in the English reading comprehension test scores. The findings of self-regulated learning strategies show that the upper level group actively used selfregulated learning strategies in all three categories of self-regulated learningmetacognitive, performance and learning environment regulation. That is, these students appeared to be proactive in their learning. Nevertheless, during the three phases of self-regulated learningforethought, performance or volitional control, and self-reflection - the students' use of self-regulated learning strategies was inconsistent. The high frequency of self-regulated learning strategies in verbal protocols also demonstrates that the lower level group may use compensatory processing to assist its low reading comprehension abilities. The findings also suggest the need for the instruction of critical reading comprehension.

\section{Acknowledgement}

This study was funded by the Thailand Research Fund through the Royal Golden Jubilee Ph.D. Program (Grant No. PHD/0020/2549).

\section{References}

Anderson, N. 1991. Individual Differences in Strategy Use in Second Language Reading and Testing. Modern Language Journal 75: 460-72.

Anderson, R. C. 1996. Research Foundations to Support Wide Reading. In Promoting Reading in Developing Countries, edited by V. Greaney, pp. 55-77. Newark, DE: International Reading Association.

Baker, L. 2002. Metacognition in Comprehension Instruction. In Comprehension Instruction Research Based Best Practices, edited by C.C. Block and M. Pressley. New York: The Guilford Press.

Bandura, A. 1986. Social Foundation of Thought and Action. New Jersey: Prentice Hall Regents.

---. 1991. Social Cognitive Theory of SelfRegulation. Organizational Behavior and Human Decision Processes 50: 248-287.

Bell, T. 2001. Extensive Reading: Speed and Comprehension. The Reading Matrix 1.1: 1-13. January 20, 2005 
$<$ http://www.readingmatrix.com/ articles/bell/index.html>

Bernhardt, E. B. 2005. Progress and Procrastination in Second Language Reading. Annual Review of Applied Linguistics 25: 133-150.

Brown, R. 2002. Straddling Two Worlds: Self-directed Comprehension Instruction for Middle Schoolers. In Comprehension Instruction Research Based Best Practices, edited by C.C. Block and M. Pressley. New York: The Guilford Press.

Cho, K. S. and S. Krashen. 1994. Acquisition of Vocabulary from the Sweet Valley Kids Series: Adult ESL Acquisition. Journal of Reading 37: 662-667.

Coady, J. 1997. L2 Vocabulary Acquisition through Extensive Reading. In Second Language Vocabulary Acquisition, edited by $\mathrm{J}$. Coady and T. Huckin. New York: Cambridge University Press.

Cunningham, A. E. and K. E. Stanovich. 1991. Tracking the Unique Effects of Print Exposure in Children: Associations with Vocabulary, General Knowledge, and Spelling. Journal of Educational Psychology 83: 264274.

Day, R. R. and J. Bamford. 1998. Extensive Reading in the Second Language Classroom. Cambridge: Cambridge University Press.

Day, R. and J. Bamford. 2000. Reaching Reluctant Readers. Forum 38.3: 12.

Educational Testing Service. 2004.
Mapping TOEFL, TSE, TWE, and TOEIC on the Common European Framework. October 25, 2007 $<$ http://www.ets.org/Media/ Research/pdf/CEF_Mapping_Study _Interim_Report.pdf $>$

---. 2007. Test and Score Data Summary for TOEFL Computer-based and Paper-based Tests. January 30, 2008 $<$ http://www.ets.org/Media/ Research/pdf/TOEFL-SUM-0506CBT.pdf.>

Eskey, D. E. 1987. Conclusion. In Research in Reading in English as a Second Language, edited by J. Devine, P.L. Carrell and D.E. Eskey. Washington, DC: Teachers of English to Speakers of Other Languages.

Fraenkel, J. R. and N. E. Wallen. 2000. How to Design and Evaluate Research in Education. Boston: McGraw-Hill Higher Education.

Grabe, W. 2002. Reading in a Second Language. In The Oxford Handbook of Applied Linguistics, edited by R.B. Kaplan. New York: Oxford University Press.

Grabe, W. and F. L. Stoller. 1997. Content-based Instruction: Research Foundations. In The Content-based Classroom: Perspectives on Integrating Language and Content, edited by T. A. Snow and D. T. Brinton, pp. 5-21. White Plains, NY: Longman.

Greaney, V. 1996. Reading in Developing Countries: Problems and Issues. In Promoting Reading in Developing Countries, edited by V. Greaney. Delaware: International 
Reading Association.

Hayashi, K. 1999. Reading Strategies and Extensive Reading in EFL Classes. RELC Journal 30.2: 114-131.

Hudson, T. 2007. Teaching Second Language Reading. New York: Oxford University Press.

Kern, R. G. 1989. Second Language Reading Strategy Instruction: Its Effects on comprehension and Word Inference Ability. The Modern Language Journal 73: 135-49.

Krashen, S. D. 2003. Explorations in Language Acquisition and Use. Portsmouth, NH: Heinemann.

---. 2004. The Power of Reading. Portsmouth: Heinemann.

---. 2007. Extensive Reading in English as a Foreign Language by Adolescents and Young Adults: A Meta-analysis. The International Journal of Foreign Language Teaching 3.2: 23-29.

Lituanas, P. M., G. M. Jacobs and W. A. Renandya. 1999. A Study of Extensive Reading with Remedial Reading Students. In Language instructional Issues in Asian Classrooms, edited by Y. M. Cheah and S. M. Ng, pp. 89104. Newark, DE: International Development in Asia Committee, International Reading Association.

Mason, B. and S. Krashen. 1997. Extensive Reading in English as a Foreign Language. System 25: 91-102.

Maxim, H. H. 1999. The Effects of Extensive Reading on First-semester German Students' Reading
Comprehension, Cultural Horizon and Language Proficiency. Unpublished doctoral dissertation, The University of Texas at Austin.

Morrow, L. M. and L. B. Gambrell. 2000. Literature-based Reading Instruction. In Handbook of Reading Research, edited by M. L. Kamil, P. B. Mosenthal, P. D. Pearson and R. Barr, vol. 3, pp. 563-586. Mahwah, NJ: Lawrence Erlbaum Associates.

Mulholland, R. 2006. Creating the Environment for Middle School $8^{\text {th }}$ Grade to be Engaged in Learning. The Reading Matrix 6.2: 106-115. February 12, 2008 $<$ http://www.readingmatrix.com/article s/mulholland/article.pdf $>$

Nassaji, H. 2003. Higher-level and Lower-level Text Processing Skills in Advanced ESL Reading Comprehension. The Modern Language Journal 87.2: 261-276.

Nation, P. 1997. The Language Learning Benefits of Extensive Reading. The Language Teacher 2.5: 13-16.

Nation, P. and K.W. Ming-tzu. 1999. Graded Readers and Vocabulary. Reading in a Foreign Language 12.2: 355-380.

National Statistical Office. 2005. The Reading Behavior of Population Survey 2005. Bangkok: National Statistical Office.

Nuttall, C. 1996. Teaching Reading Skills in a Foreign Language. Oxford: Heinemann.

Paris, S.D., B.A. Wasik and J.C. Turner. 
1996. The Development of Strategic Readers. In Handbook of Reading Research, edited by R. Barr, M. Kamil, P. Mosenthal and P.D. Pearson, vol. 2, pp. 609-40. Mahwah, N.J.: Lawrence Erlbaum Associates.

Perry, N.E., L. Phillips and L.R. Hutchinson. 2006. Preparing Student Teachers to Support for Self-regulated Learning. Elementary School Journal 106.3: 237-254.

Pintrich, P. R. and E. V. De Groot. 1990. Motivational and Self-regulated Learning Components of Classroom Academic Performance. Journal of Educational Psychology 82.1: 33-38.

Prapphal, K. and P. Opanon-Amata. 2002. An Investigation of English Proficiency of Thai Graduates. Chulavijai 21.3: 12-16.

Pressley, M. and P. Afflerbach. 1995. Verbal Protocols of Reading: The Nature of Constructively Responsive Reading. Hillsdale NJ: Erlbaum.

Robb, T. 2002. Extensive Reading in the Asian Context-An Alternative View. Reading in a Foreign Language 14.2: 146-147.

Schackne, S. 1994. Extensive Reading and Language Acquisition: Is there a Correlation? A Two-part Study. Paper presented at the Annual International Conference of the Institute of Language in Education, December, 1994. Hong Kong.

Schunk, D. H. and B. J. Zimmerman. 1994. Self-regulation of Learning and Performance: Issues and Educational Applications. New Jersey: Lawrence
Erlbaum Associates, Publishers.

Sheu, S. P-H. 2003. Extensive Reading with EFL Learners at Beginning Level. TESL Reporter 36.2: 27-40.

---. 2004. Students' Reflections on the Physical Features of EFL Graded Readers. TESL Reporter 37.1: 18-33.

Sims, J. M. 1996. A Comparative Study of Improvements in Reading Comprehension of Skills-based Instruction and Extensive Reading for Pleasure with Taiwanese Freshmen University Students. Unpublished doctoral dissertation, The Florida State University.

Smith, K. 2006. A Comparison of "pure" Extensive reading with Intensive Reading and Extensive Reading with Supplementary Activities. The International Journal of Foreign Language Teaching 2.2: 12-15.

Stanovich, K. E. 2000. Progress in Understanding Reading: Scientific Foundations and New Frontiers. New York: The Guilford Press.

Susser, B. and T. N. Robb. 1990. EFL Extensive Reading Instruction: Research and procedure. JALT Journal 12.2: 161-185.

Takase, A. 2001. What Motivates Japanese Students to Read English Books? The Proceedings of the Third Temple University Japan Applied Linguistics Colloquium, pp. 67-77. Tokyo: Temple University Japan.

---. 2003. The Effects of Extensive Reading on the Motivation of Japanese High School Students. Unpublished dissertation. UMI AAT 3097732 
Tanaka, H. and P. Stapleton. 2007. Increasing Reading Input in Japanese High School EFL Classrooms: An Empirical Study Exploring the Efficacy of Extensive Reading. The Reading Matrix 7.1: 115-131. February 12, $2008<$ http://www.reading matrix.com/articles/tanaka_stapleton/ article.pdf $>$

Tella, A. and S. Akande. 2007. Children's Reading Habits and Availability of Books in Botswana Primary Schools: Implications for Achieving Quality Education. The Reading Matrix 7.2: 117-142.

Walker, C. 1997. A Self Access Extensive Reading Project Using Graded Readers (with particular reference to students of English for academic purposes). Reading in a Foreign Language 11.1: 121-149.

Winne, P. H. and N. E. Perry. 2000. Measuring Self-regulated Learning. In Handbook of Self-regulation, edited by M. Boekaerts, P.R. Pintrich and M. Zeidner. San Diego: Academic Press.

Winne, P. H. and D. B. Stockley. 1998. Computing Technologies as Sites for Developing Self-regulated Learning. In Self-regulated Learning. From Teaching to Self-reflective Practice, edited by D. H. Schunk and B. J. Zimmermann. New York: The Guilford Press.

Zimmerman, B. J. 1989. A Social Cognitive View of Self-regulated Academic Learning. Journal of Educational Psychology 81.3: 329339.

---. 2000. Attaining Self- regulation:
A Social Cognitive Perspective. In Handbook of Self-regulation, edited by M. Boekaerts, P.R. Pintrich and M. Zeidner. San Diego: Academic Press.

Zimmerman, B. J., S. Bonner and R. Kovach. 2003. Developing SelfRegulated Learners. Beyond Achievement to Self-efficacy. Washington DC: American Psychological Association.

Zimmerman, B. J. and M. Martinez-Pons. 1986. Development of a Structured Interview for Assessing Students' Use of Self-regulated Learning Strategies. American Educational Research Journal 23: 614-628.

---. 1988. Construct Validation of a Strategy Model of Student SelfRegulated Learning. Journal of Educational Psychology 80: 284-290. 